\title{
ARM
}

CLIMATE RESEARCH FACILITY

\section{C-Band Scanning ARM Precipitation Radar (C-SAPR)}

\section{$\mathrm{HANDBOOK}$}

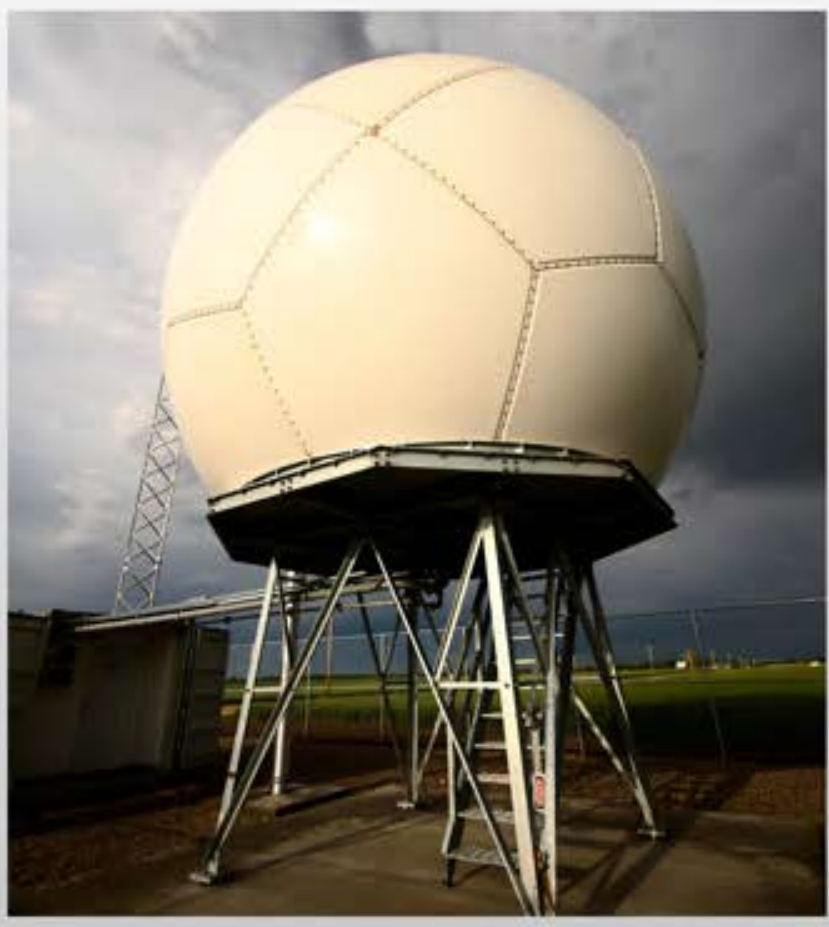

November 2012 


\section{DISCLAIMER}

This report was prepared as an account of work sponsored by the U.S. Government. Neither the United States nor any agency thereof, nor any of their employees, makes any warranty, express or implied, or assumes any legal liability or responsibility for the accuracy, completeness, or usefulness of any information, apparatus, product, or process disclosed, or represents that its use would not infringe privately owned rights. Reference herein to any specific commercial product, process, or service by trade name, trademark, manufacturer, or otherwise, does not necessarily constitute or imply its endorsement, recommendation, or favoring by the U.S. Government or any agency thereof. The views and opinions of authors expressed herein do not necessarily state or reflect those of the U.S. Government or any agency thereof. 


\title{
C-Band Scanning ARM Precipitation Radar (C-SAPR) Handbook
}

\author{
K Widener \\ N Bharadwaj
}

November 2012

Work supported by the U.S. Department of Energy,

Office of Science, Office of Biological and Environmental Research 


\section{Acronyms and Abbreviations}

\begin{tabular}{|c|c|}
\hline$\phi_{\mathrm{DP}}$ & differential phase \\
\hline$\rho_{\mathrm{HV}}$ & correlation coefficient between $\mathrm{H}$ and $\mathrm{V}$ polarizations \\
\hline ARM & Atmospheric Radiation Measurement (Program) \\
\hline C band & frequencies between $4 \mathrm{GHz}$ and $8 \mathrm{GHz}$ \\
\hline $\mathrm{dB}$ & decibel \\
\hline $\mathrm{dBi}$ & antenna gain referenced to isotropic radiator \\
\hline $\mathrm{dBm}$ & decibel referenced to $1 \mathrm{~mW}$ \\
\hline $\mathrm{dBZ}$ & reflectivity \\
\hline DQ & Data Quality \\
\hline $\mathrm{GHz}$ & gigahertz $\left(10^{9} \mathrm{~Hz}\right)$ \\
\hline $\mathrm{Hz}$ & hertz \\
\hline Ka band & frequencies between $26.5 \mathrm{GHz}$ and $40 \mathrm{GHz}$ \\
\hline $\mathrm{K}_{\mathrm{DP}}$ & specific differential phase \\
\hline $\mathrm{kW}$ & kilowatt \\
\hline L band & frequencies between $1 \mathrm{GHz}$ and $2 \mathrm{GHz}$ \\
\hline $\mathrm{m}$ & meter \\
\hline $\mathrm{MHz}$ & megahertz $\left(10^{6} \mathrm{~Hz}\right)$ \\
\hline MMW & millimeter wave (30GHz - 300GHz) \\
\hline $\mathrm{mW}$ & milliwatt \\
\hline NCAR & National Center for Atmospheric Research \\
\hline PPI & Plan Position Indicator \\
\hline PRF & pulse repetition frequency \\
\hline RHI & Range Height Indicator \\
\hline $\mathrm{S}$ band & frequencies between $2 \mathrm{GHz}$ and $4 \mathrm{GHz}$ \\
\hline SGP & Southern Great Plains \\
\hline TWP & Tropical Western Pacific \\
\hline W band & frequencies between $75 \mathrm{GHz}$ and $110 \mathrm{GHz}$ \\
\hline $\mathrm{X}$ band & frequencies between $8 \mathrm{GHz}$ and $12 \mathrm{GHz}$ \\
\hline X-SAPR & X-band scanning ARM precipitation radar \\
\hline $\mathrm{Z}_{\mathrm{DR}}$ & differential reflectivity \\
\hline $\mathrm{Z}_{\mathrm{H}}$ & horizontal reflectivity \\
\hline $\mathrm{Z}_{\mathrm{V}}$ & vertical reflectivity \\
\hline
\end{tabular}




\section{Contents}

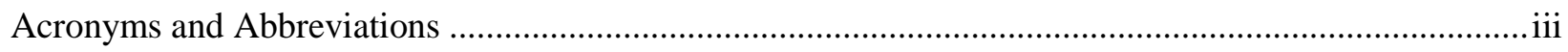

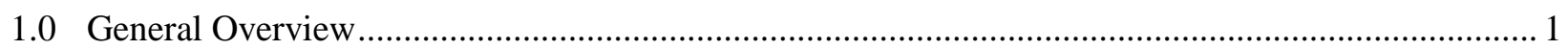

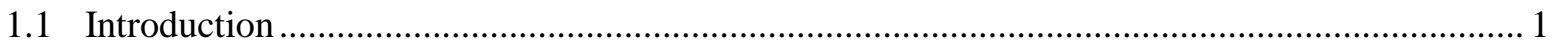

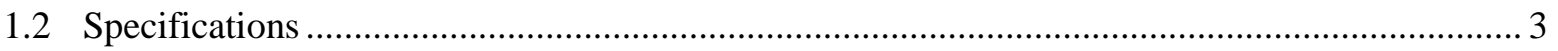

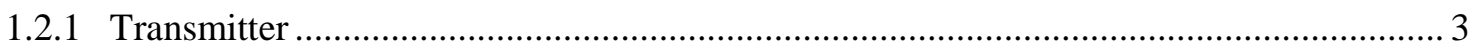

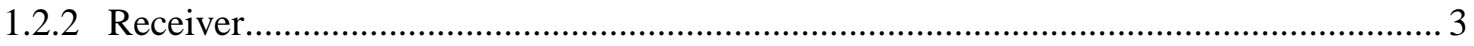

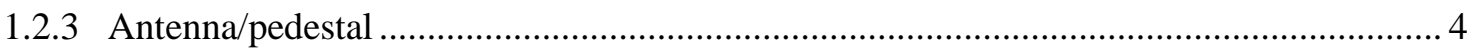

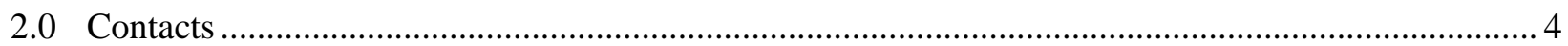

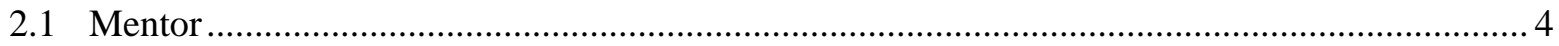

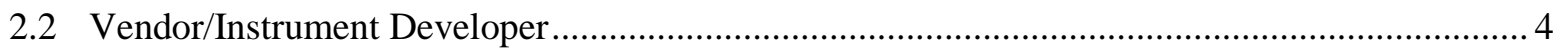

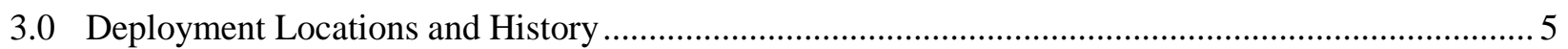

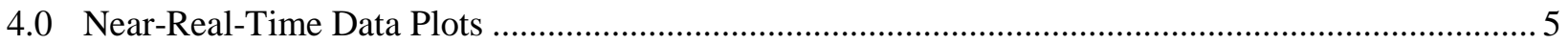

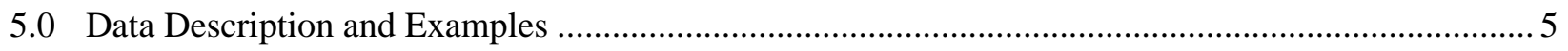

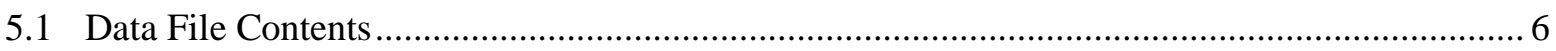

5.1.1 Primary Variables and Expected Uncertainty ........................................................... 6

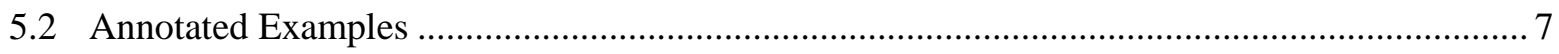

5.3 User Notes and Known Problems …................................................................................... 7

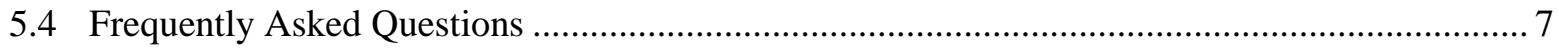

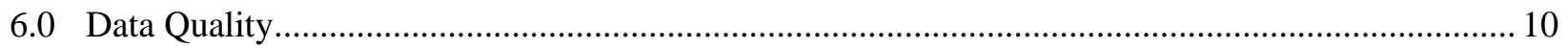

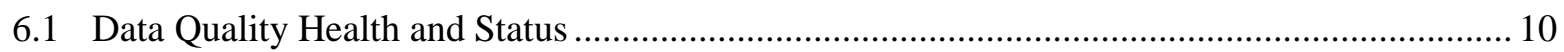

6.2 Data Reviews by Instrument Mentor................................................................................. 10

6.3 Data Assessments by Site Scientist/Data Quality Office ........................................................ 10

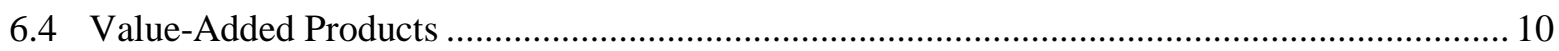

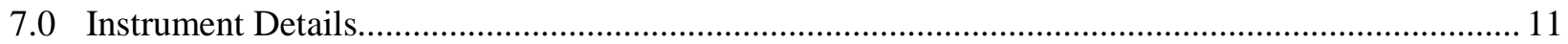

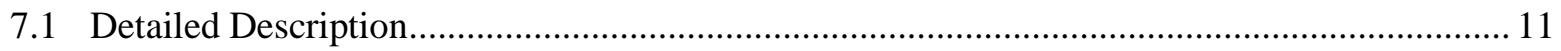

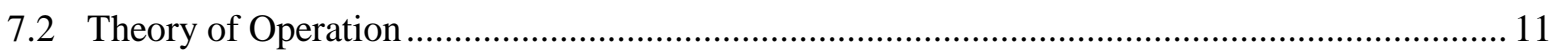

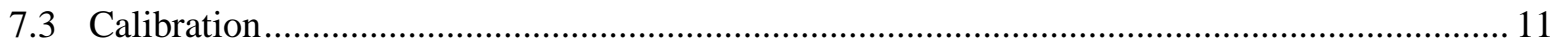

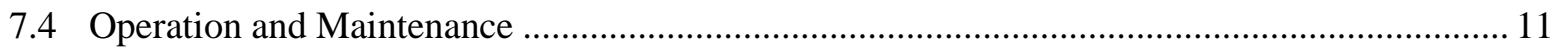

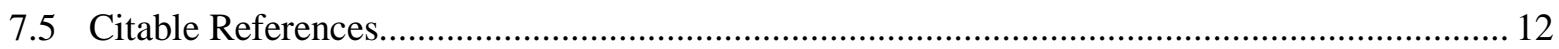




\section{Figures}

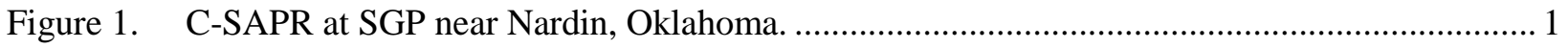

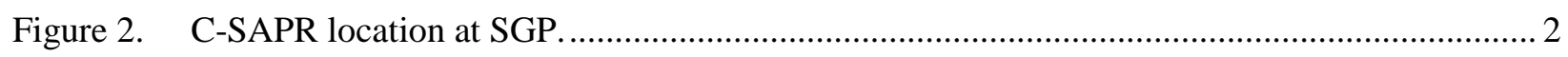

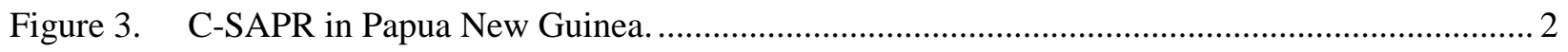

Figure 4. C-SAPR location in Papua New Guinea. ..................................................................... 3

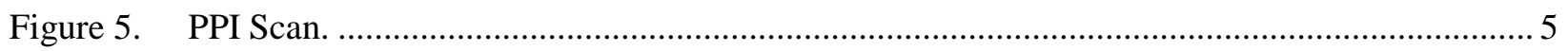

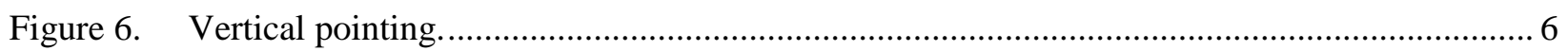

Figure 7. Dielectric function of water as a function of frequency and temperature. .............................. 8

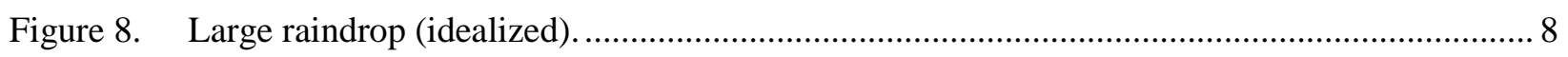

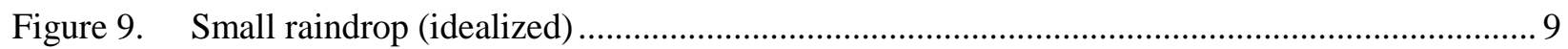

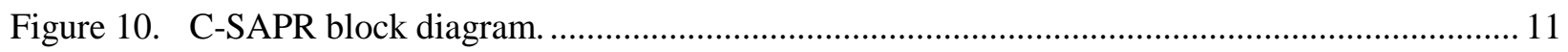




\subsection{General Overview}

\subsection{Introduction}

The C-band scanning ARM precipitation radar (C-SAPR) (Figure 1) is a scanning polarimetric Doppler radar transmitting simultaneously in both $\mathrm{H}$ and $\mathrm{V}$ polarizations. With a 350-kW magnetron transmitter, this puts $125 \mathrm{~kW}$ of transmitted power for each polarization. The receiver for the C-SAPR is a National Center for Atmospheric Research (NCAR) -developed Hi-Q system operating in a coherent-on-receive mode.

The ARM Climate Research Facility operates two C-SAPRs; one of them is deployed near the Southern Great Plains (SGP) Central Facility (Figure 2) near the triangular array of X-SAPRs, and the second CSAPR is deployed at ARM's Tropical Western Pacific (TWP) site on Manus Island in Papua New Guinea.

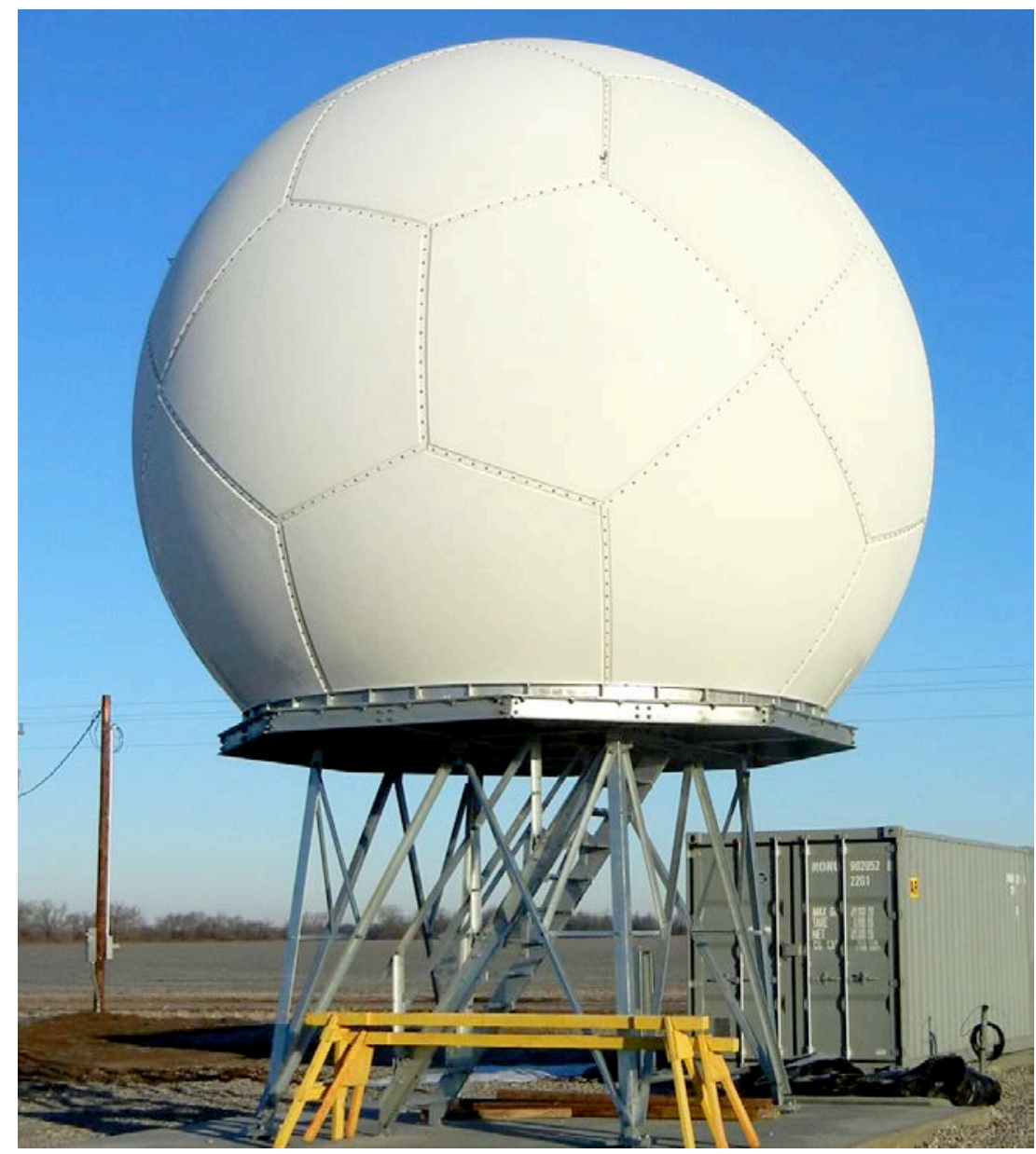

Figure 1. C-SAPR at SGP near Nardin, Oklahoma. 


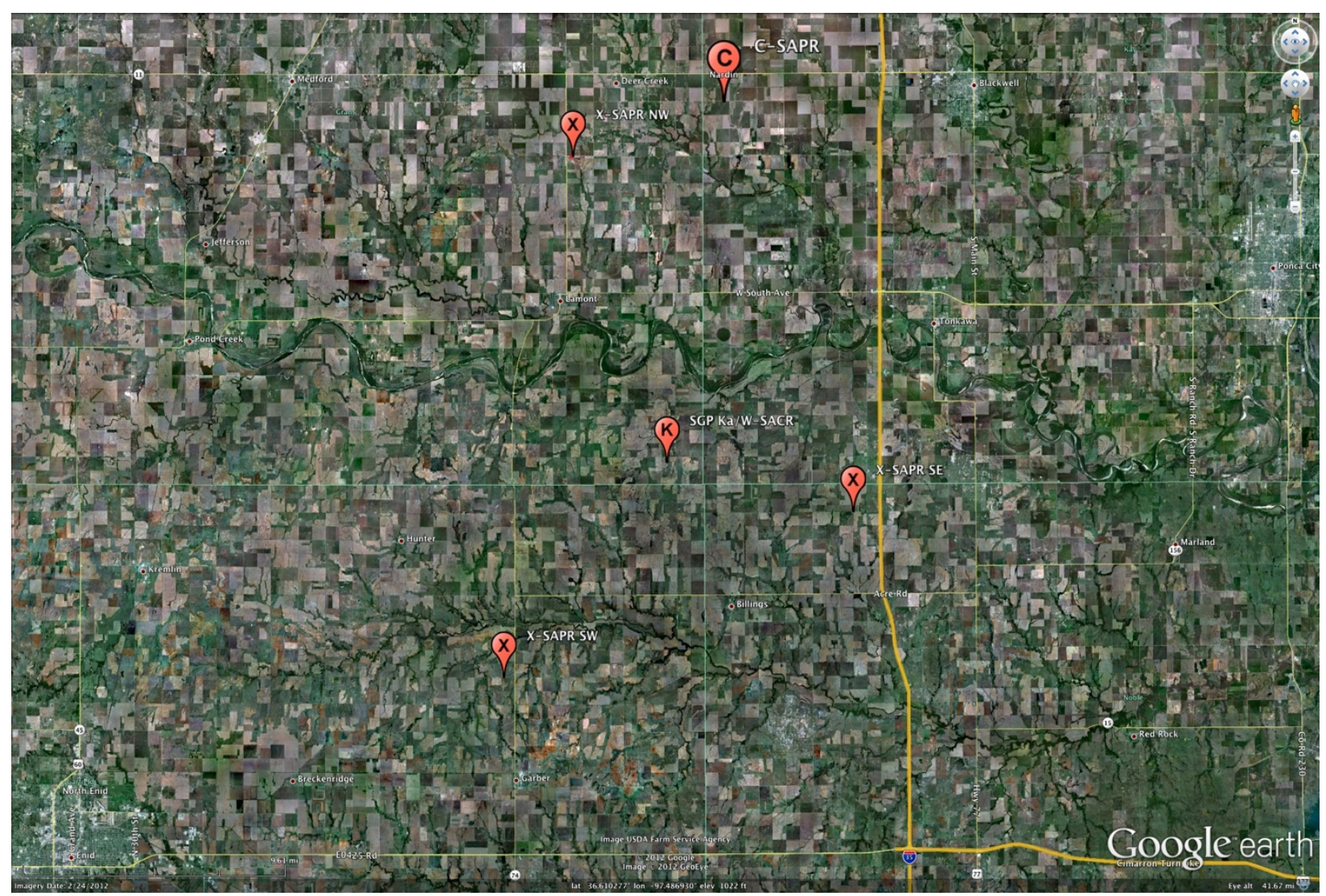

Figure 2. C-SAPR location at SGP.

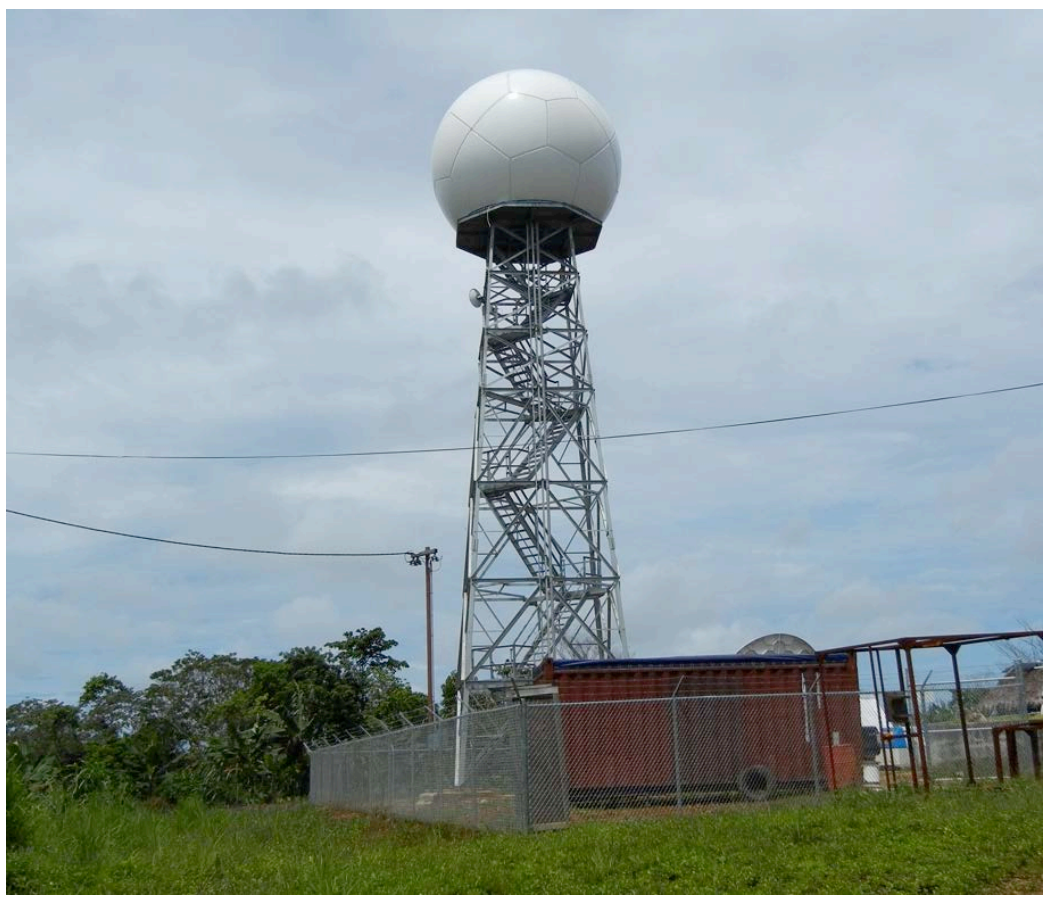

Figure 3. C-SAPR in Papua New Guinea. 


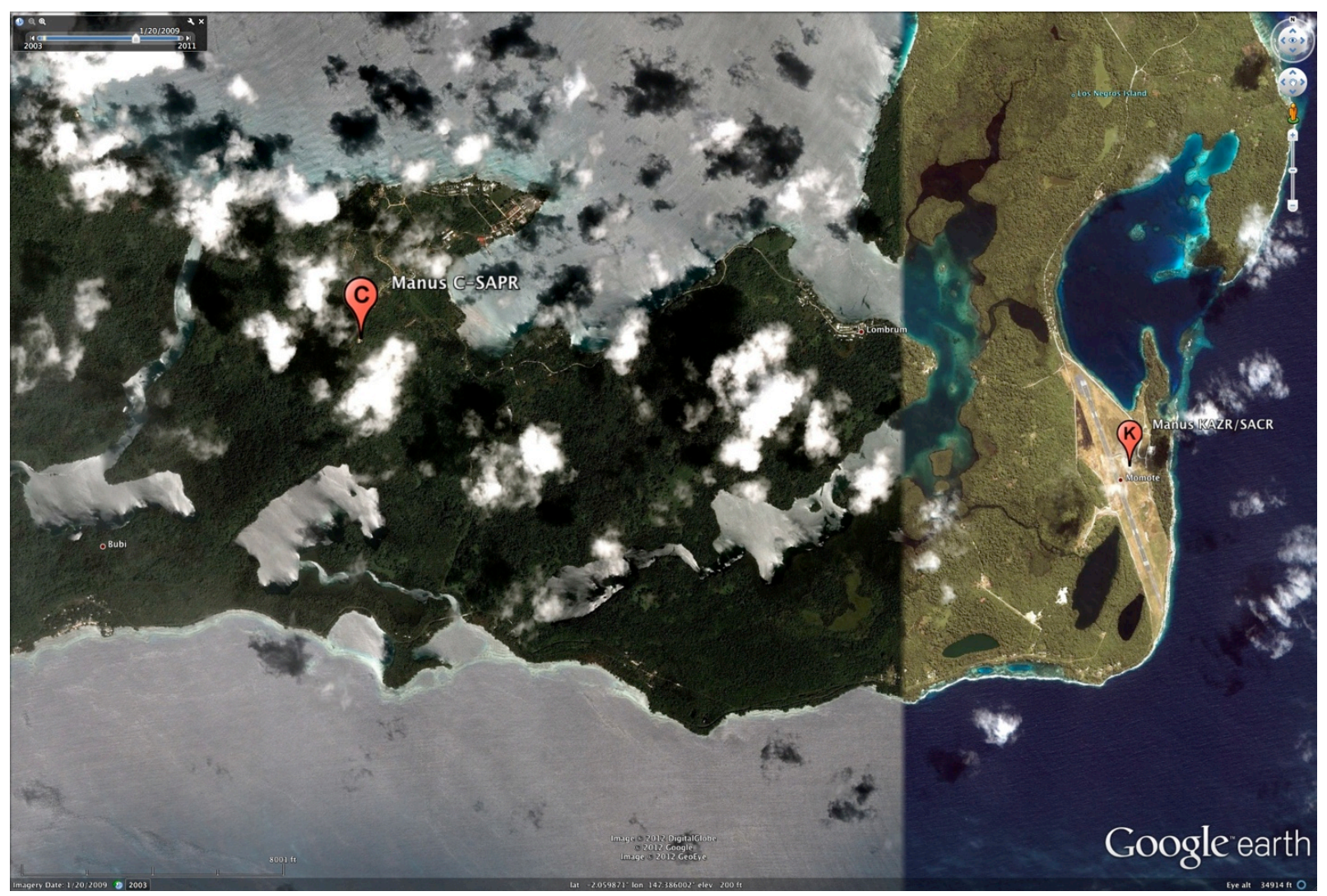

Figure 4. C-SAPR location in Papua New Guinea.

\subsection{Specifications}

\subsubsection{Transmitter}

Type:

Center frequency:

Peak power output:

Pulse width:

Polarization:

Maximum duty cycle:

PRF:

Manufacturer:

\subsubsection{Receiver}

Type:

Dynamic range:

Noise figure:

Sampling rate:

Decimation factor:

Video bandwidth:

Processing software:

Manufacturer:
Magnetron

$6.25 \mathrm{GHz}$

$350 \mathrm{~kW}$

$200 \mathrm{~ns}-2 \mu \mathrm{s}$

dual polarization, simultaneous $\mathrm{H}$ and $\mathrm{V}$

$0.1 \%$

$200 \mathrm{~Hz}-2.7 \mathrm{kHz}$

Pulse Systems Technology

coherent-on-receive, dual channel digital Hi-Q

$>80 \mathrm{~dB}$

$2.8 \mathrm{~dB}$

$40 \mathrm{MHz}$

Adjustable

Adjustable

TITAN

NCAR 


\subsubsection{Antenna/pedestal}

$\begin{array}{ll}\text { Antenna Type: } & \text { direct feed parabolic reflector } \\ \text { Diameter: } & 2.4 \mathrm{~m} \\ 3 \mathrm{~dB} \text { beam width: } & 0.9^{\circ} \\ \text { Gain: } & 45.1 \mathrm{dBi} \\ \text { Cross polarization isolation: } & -32 \mathrm{~dB} \\ \text { 2-way radome loss: } & <1.0 \mathrm{~dB} \\ \text { Pedestal Type: } & \text { azimuth over elevation } \\ \text { Azimuth scan rate: } & \text { up to } 36 \% \mathrm{~s} \\ \text { Elevation scan rate: } & \text { up to } 30^{\circ} / \mathrm{s} \\ \text { Pedestal manufacturer: } & \text { ARC }\end{array}$

\subsection{Contacts}

\subsection{Mentor}

Kevin Widener

Pacific Northwest National Laboratory

412 Hale Drive

Underwood, WA 98651

Phone: 509-375-2487

Fax: 509-375-6736

Email: kevin.widener@pnnl.gov

Nitin Bharadwaj

Pacific Northwest National Laboratory

P.O. Box 999

Richland, WA 99352

Phone: 509-372-4267

Fax: 509-375-6736

Email: nitin@pnnl.gov

\subsection{Vendor/Instrument Developer}

Advanced Radar Corporation (ARC)

2150 W. 6th Ave.

Broomfield, CO 80020

Website: http://www.radar-sales.com/ 


\subsection{Deployment Locations and History}

\begin{tabular}{|l|c|c|c|c|c|}
\hline \multicolumn{1}{|c|}{ Location } & $\begin{array}{c}\text { Direction } \\
\text { from CF }\end{array}$ & $\begin{array}{c}\text { Site } \\
\text { Designation }\end{array}$ & $\begin{array}{c}\text { Date } \\
\text { Installed }\end{array}$ & $\begin{array}{c}\text { Date } \\
\text { Removed }\end{array}$ & Status \\
\hline Nardin, OK & NE & SGP/I7 & $02 / 18 / 2011$ & & \\
\hline Lombrum, PNG & WNW & TWP/I1 & $08 / 16 / 2011$ & & \\
\hline
\end{tabular}

\subsection{Near-Real-Time Data Plots}

See http://radar.arm.gov.

\subsection{Data Description and Examples}

There are many different types of scans that the C-SAPR can perform. Scan strategies are defined for each site that alternate between the following types of scans:

- RHI (Range Height Indicator) scans are scans in which the azimuth axis is held constant while the elevation axis is changed. An RHI scan can go horizon-to-horizon over 180 degrees of elevation or a subset of that. The C-SAPR is limited to scanning 92 degrees in elevation.

- PPI (Plan Position Indicator) scans are what are typically thought of when thinking about weather radars. These are scans in which the elevation is scanned for 360 degrees and then the elevation is incremented. Figure 5 shows a scan with four different elevations.

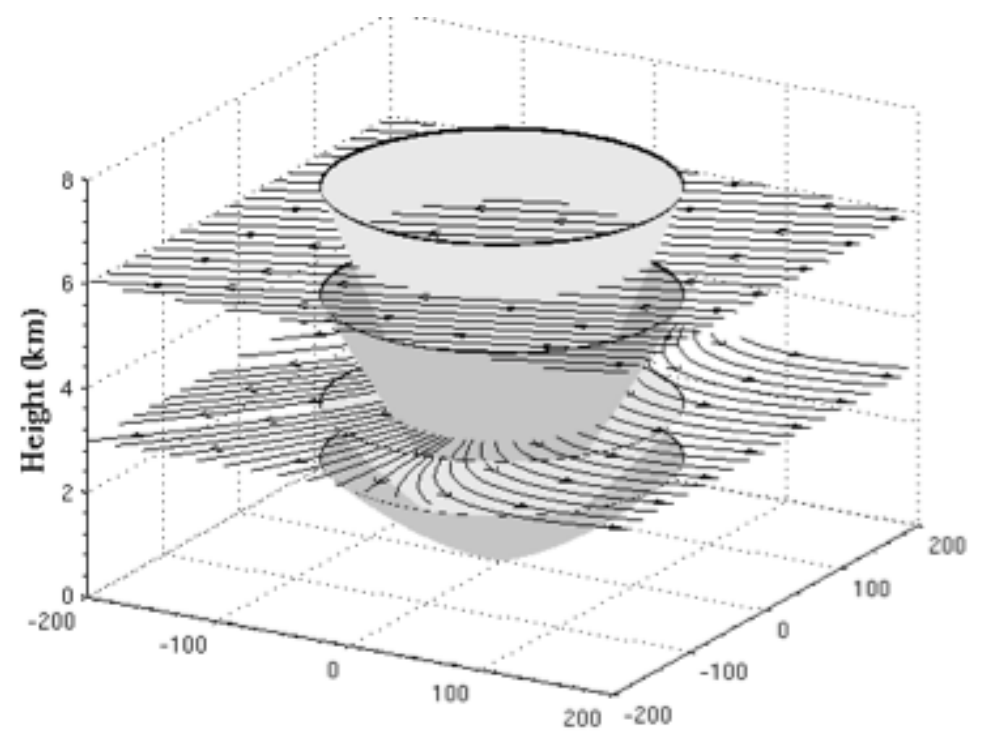

Figure 5. PPI Scan. 


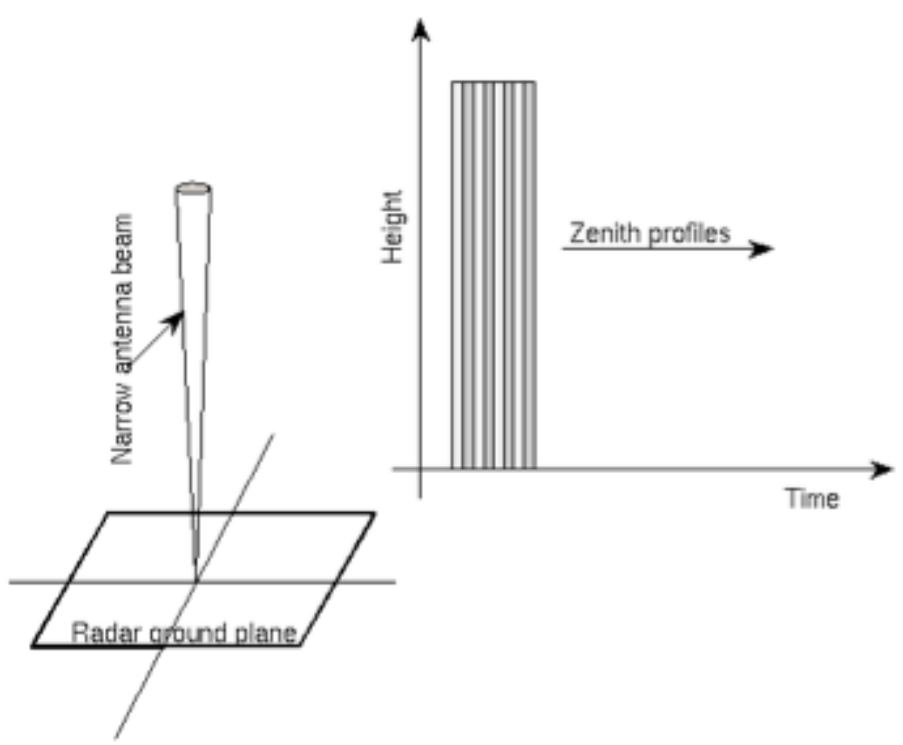

Figure 6. Vertical pointing.

- Vertical pointing - during part of the measurement period, ARM plans on operating the C-SAPR in a vertical pointing mode to obtain zenith cloud profiles profiles similar to those obtained by the Kaband ARM zenith radar and W-band ARM cloud radar. Figure 6 shows an example of this type of scan.

\subsection{Data File Contents}

For the time being, ARM has decided to not ingest the C-SAPR data into netCDF. C-SAPR data are stored in the MDV format developed by NCAR. Data file descriptions are given in NCAR'S TITAN documentation. TITAN information is available at:

http://www.ral.ucar.edu/projects/titan/docs/

To obtain a text dump of an MDV file, retrieve a sample file from the ARM Data Archive and run the TITAN "PrintMdv" program.

\subsubsection{Primary Variables and Expected Uncertainty}

V Linear channel Doppler mean velocity

W Linear channel Doppler spectrum width

Z Log channel reflectivity corrected for clutter

$\mathbf{Z}_{\text {DR }} \quad$ Differential reflectivity

$\phi_{\text {DP }} \quad$ Differential phase

$\mathrm{K}_{\mathrm{DP}} \quad$ Specific Differential phase

$\rho_{\mathrm{HV}} \quad$ Dual-polarization correlation magnitude

NCP Normalized coherent power 


\subsection{Annotated Examples}

To be determined.

\subsection{User Notes and Known Problems}

To be determined.

\subsection{Frequently Asked Questions}

What is the meteorological radar range equation?

This is the equation to determine the reflectivity and is usually given in decibels of $\mathrm{Z}$ or $\mathrm{dBZ}$.

$$
Z=10 \log \left(\frac{1024 \ln (2) \lambda^{2} R^{2} P_{r} L_{a} L_{s y s}}{10^{-18} c \tau \pi^{3} G_{0}^{2}\left|K_{w}\right|^{2} \theta_{3 d B}^{2} P_{t}}\right) \quad d B Z
$$

where:

$$
\begin{aligned}
& \mathrm{Z}=\text { reflectivity }(\mathrm{dBZ}) \\
& \lambda=\text { wavelength }(\mathrm{m}) \\
& \mathrm{R}=\text { range }(\mathrm{m}) \\
& \mathrm{P}_{\mathrm{r}}=\text { received power (watts) } \\
& \mathrm{L}_{\mathrm{a}}=\text { two-way atmospheric loss } \\
& \mathrm{L}_{\mathrm{sys}}=\text { radar system losses } \\
& \mathrm{C}=\text { speed of light }(\mathrm{m} / \mathrm{s}) \\
& \tau=\text { pulse width (s) } \\
& \mathrm{G}_{\mathrm{o}}=\text { antenna gain } \\
& \left|\mathrm{K}_{\mathrm{w}}\right|^{2}=\text { index of refraction factor for liquid water at } 0^{\circ} \mathrm{C} \\
& \theta_{3 \mathrm{~dB}}=\text { antenna beamwidth } \\
& \mathrm{P}_{\mathrm{t}}=\text { transmit power (watts) }
\end{aligned}
$$

What dielectric factor for water is used to computer reflectivity in the radar range equation $/ K_{w} / 2$ ?

The dielectric factor of water is a function of frequency and temperature of water drops as shown in Figure 7. 


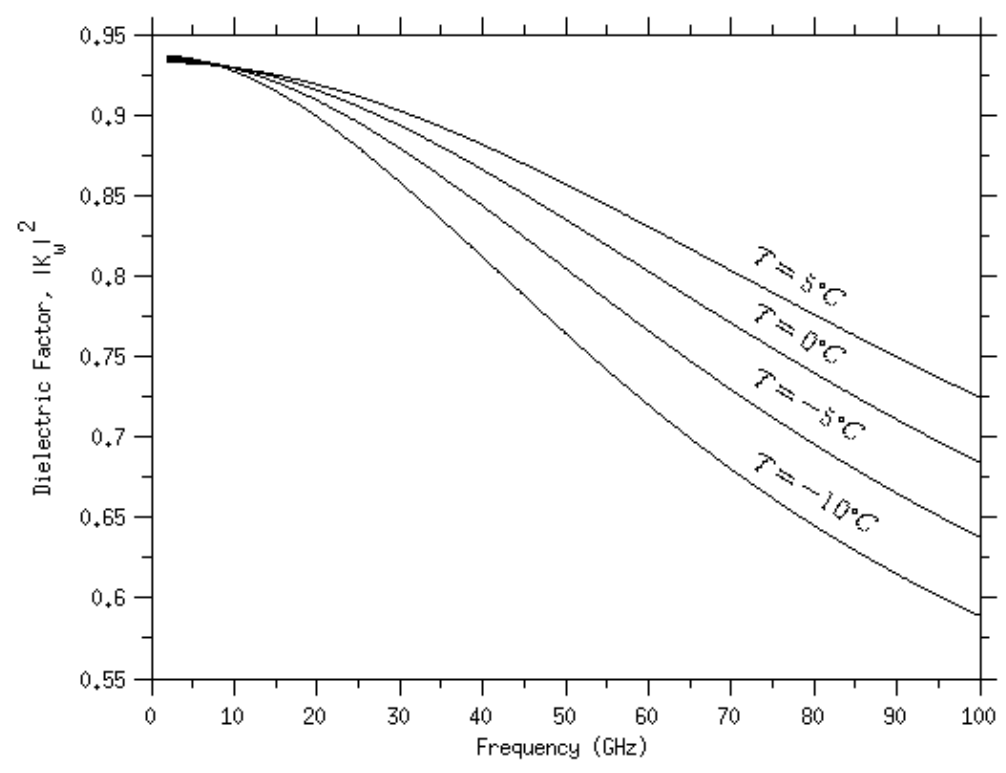

Figure 7. Dielectric function of water as a function of frequency and temperature.

The dielectric factor of water at $0^{\circ} \mathrm{C}$ is used for the computation of equivalent reflectivity factor. The value of dielectric factor used is 0.93 for the C-SAPR.

What are measurements are made with a dual-polarization radar versus that of a single polarization radar?

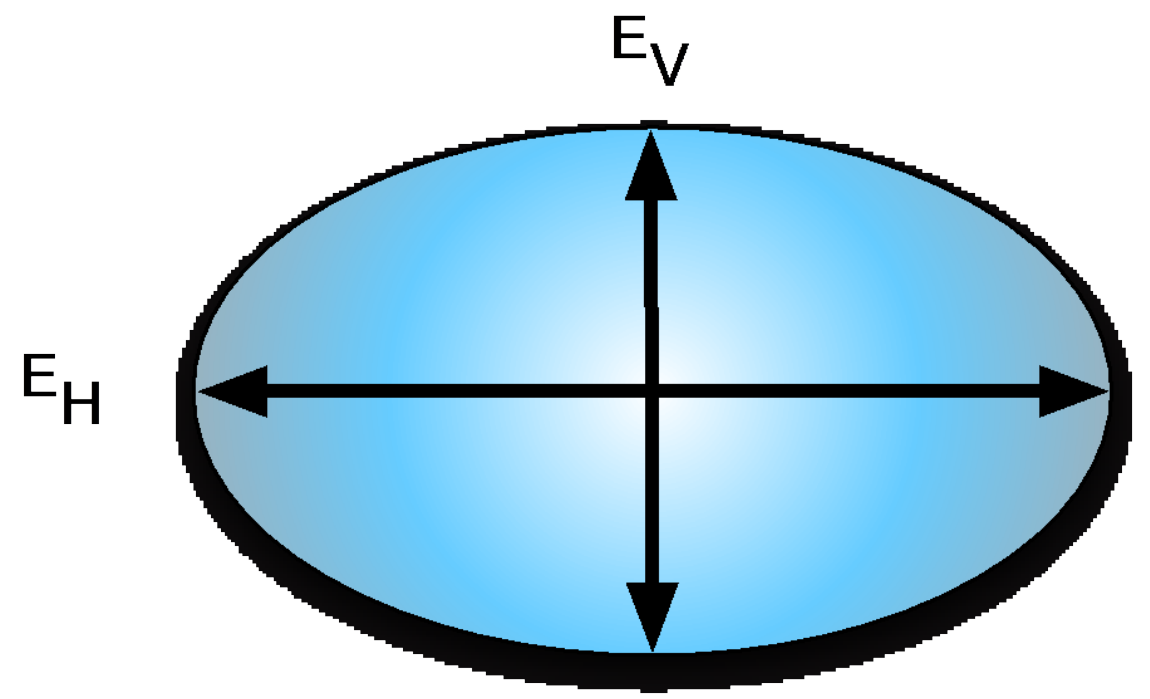

Figure 8. Large raindrop (idealized).

All Doppler weather radars provide a measurement of equivalent radar reflectivity factor (colloquially just reflectivity). Single-polarization radars cannot distinguish much in the way of the type of hydrometeor being observed. They also have varying degrees of success in estimating rainfall rates, and they depend on empirically derived parametric models to do this. These models are different for differing climatic regimes. The promise of dual-polarization techniques is to alleviate some of these shortcomings. 
To understand the role of dual-polarization radars in meteorology, it is useful to consider the shape of water droplets. First you must realize they are not spherical, nor are they shaped like the customary teardrop. Water drops are roughly oblate spheroids. The larger the drop, the larger the horizontal axis is with respect to the vertical axis (Figure 8). Smaller drops are much closer to being spherical (Figure 9).

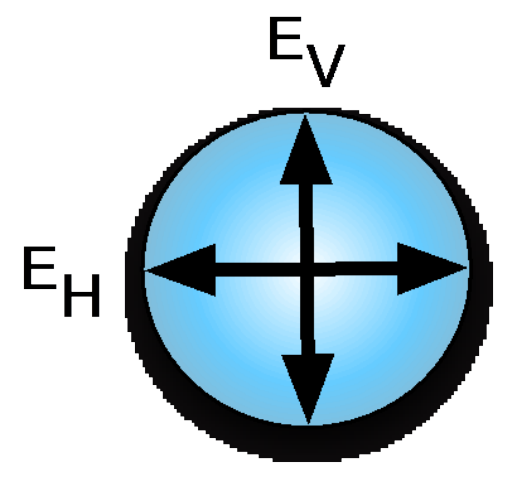

Figure 9. Small raindrop (idealized)

Keeping in mind the oblateness of raindrops, dual polarization adds the ability to measure the following variables:

- Horizontal reflectivity $\left(\mathrm{Z}_{\mathrm{H}}\right)$ is a measurement of the reflectivity in the horizontal polarization plane. One can see that for large raindrops, the reflectivity in the horizontal axis is going to be much larger than that in the vertical axis, i.e., more oblate the larger the drop is.

- Vertical reflectivity $\left(\mathrm{Z}_{\mathrm{V}}\right)$ is a measurement of the reflectivity in the vertical polarization plane. As the raindrop gets smaller, it becomes more like a sphere, i.e., less oblate the smaller the drop is.

- Differential reflectivity $\left(\mathrm{Z}_{\underline{\mathrm{DR}}}\right)$ is the ratio of the horizontal reflectivity $\left(\mathrm{Z}_{\mathrm{H}}\right)$ to the vertical reflectivity $\left(Z_{\mathrm{v}}\right)$. For large water drops, $\mathrm{Z}_{\mathrm{H}}>\mathrm{Z}_{\mathrm{v}}$ and $\mathrm{Z}_{\mathrm{DR}}>0 \mathrm{~dB}$. For small drops, $\mathrm{Z}_{\mathrm{H}} \approx \mathrm{Z}_{\mathrm{v}}$ and $\mathrm{Z}_{\mathrm{DR}} \approx 0 \mathrm{~dB}$. What about ice in the form of hail? Although hail is irregularly shaped, as it tumbles during its rise and fall in the atmosphere, it looks close to spherical and its $\mathrm{Z}_{\mathrm{DR}} \approx 0 \mathrm{~dB}$. $\mathrm{Z}_{\mathrm{DR}}$ is unitless and reported in $\mathrm{dB}$.

- Differential phase ( $\left.\phi_{\underline{D P}}\right)$ is the measured cumulative differential phase shift between the horizontal signal $\left(\phi_{\mathrm{HH}}\right)$ and the vertical signal $\left(\phi_{\mathrm{VV}}\right)$. As the radar signal goes through water, its speed is reduced for that period of time it is in a raindrop inducing a phase delay in the signal. In large oblate drops, this phase delay, also called phase shift, is larger than smaller, less oblate drops. $\phi_{\mathrm{DP}}$ is measured in degrees.

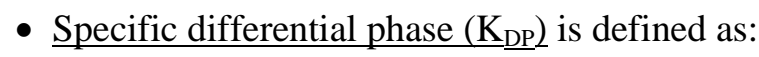

$$
K_{D P}=\frac{\phi_{D P}\left(r_{2}\right)-\phi_{D P}\left(r_{1}\right)}{2\left(r_{2}-r_{1}\right)}\left(\frac{\mathrm{deg}}{\mathrm{km}}\right)
$$

$\mathrm{K}_{\mathrm{DP}}$ is useful for estimating rainfall rates because it is not affected by spherical particles (i.e., tumbling hail). This allows the amount of liquid water in a rain-ice mixture to be estimated. Another important feature of $\mathrm{K}_{\mathrm{DP}}$ is that it is a propagation variable, which means it is not dependent on the amount of received power. 
- Dual-polarization correlation magnitude $\left(\rho_{\underline{\mathrm{HV}}}\right)$ is also referred to as the correlation coefficient and is a measurement of the correlation between the horizontal and vertical radar signals. $\rho_{\mathrm{HV}}$ can be useful in hydrometeor discrimination, e.g., telling the difference between rain, hail, graupel, snow, etc.

\subsection{Data Quality}

\subsection{Data Quality Health and Status}

The Data Quality Office website has links to several tools for inspecting and assessing X-SAPR data quality:

- $\underline{\text { DQ Explorer }}$

- $\underline{\text { DQ Plot Browser }}$

- NCVweb: Interactive web-based tool for viewing ARM data.

Plots of reflectivity, Doppler radial velocity, and dual-polarization variables provide a good indicator of whether the system is operational or not.

\subsection{Data Reviews by Instrument Mentor}

Instrument mentors review C-SAPR data in the following ways:

- Routine review for nominal operation, usually daily Monday-Friday

- When requested by Site Operations

- When requested by the site scientist team

- When requested by an ARM data translator

- When requested by a data user

- When notified automatically by the X-SAPR's built-in test email messages.

\subsection{Data Assessments by Site Scientist/Data Quality Office}

To be determined.

\subsection{Value-Added Products}

There are no value-added products for C-SAPR at this time. There are plans to produce a "corrected moments" product, which will include velocity and range dealiasing and water vapor attenuation correction. After that, a gridded moments product with cloud boundaries will be produced Instrument Details. 


\subsection{Instrument Details}

\subsection{Detailed Description}

Figure 10 shows the basic block diagram for the C-SAPR.

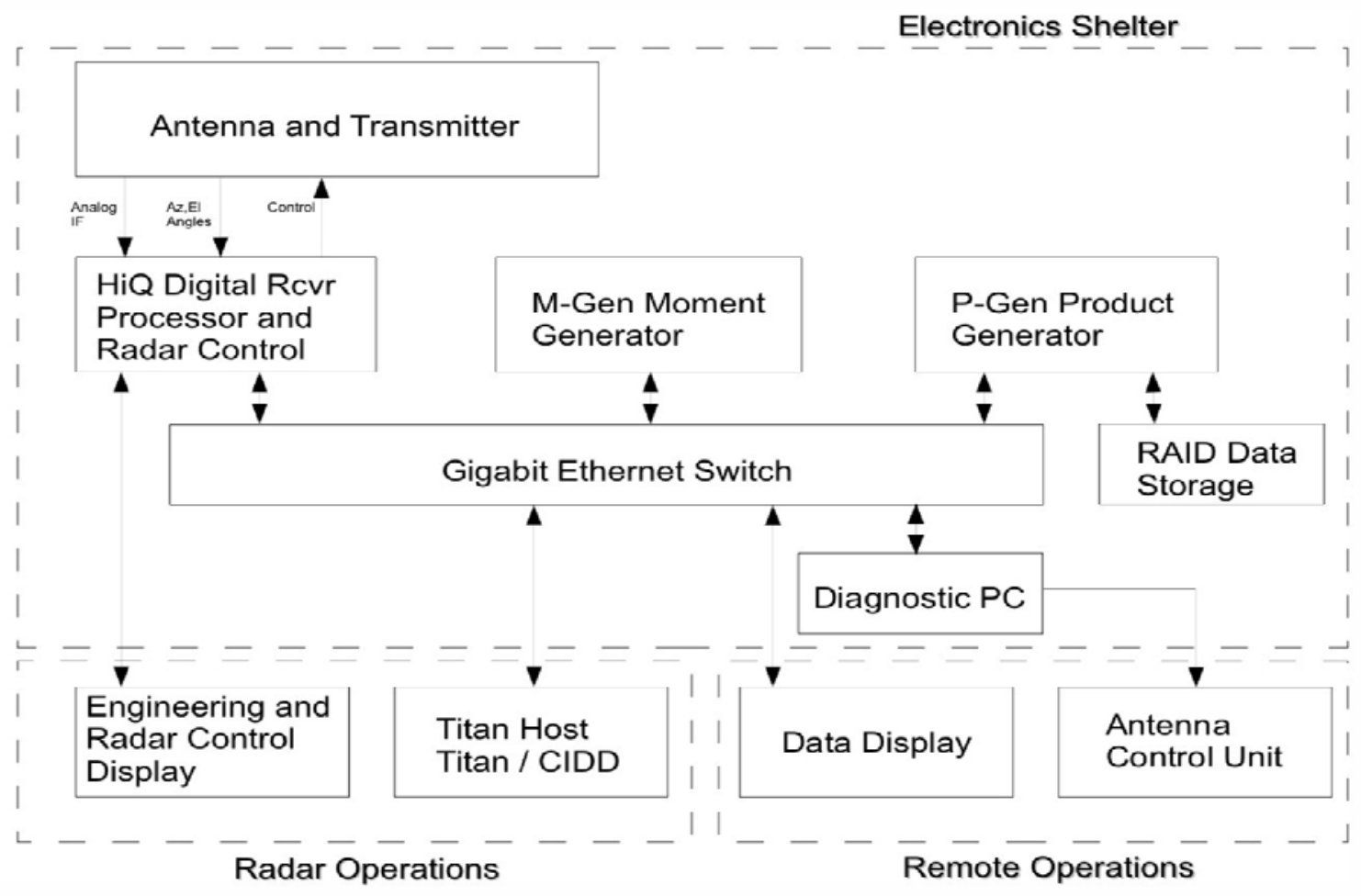

Figure 10. C-SAPR block diagram.

\subsection{Theory of Operation}

The theory of operation is available in the manufacturer's documentation. Contact the instrument mentor for information.

\subsection{Calibration}

To be included in manufacturer's documentation and the ARM Common Calibration database. Contact the instrument mentor for information.

\subsection{Operation and Maintenance}

See the NCAR TITAN documentation at http://www.rap.ucar.edu/projects/titan/home/index.php. 


\subsection{Citable References}

Bharadwaj N, K Widener, A Koontz, and K Johnson. "Data Specification for ARM Scanning Radars.” In progress.

Bringi VN, and V Chandrasekar. 2001. Polarimetric Doppler Weather Radar. Cambridge University Press, Cambridge, United Kingdom.

Doviak RJ, and DS Zrnic. 1993. Doppler Radar and Weather Observations. $2^{\text {nd }}$ Edition, Academic Press, San Diego, California 


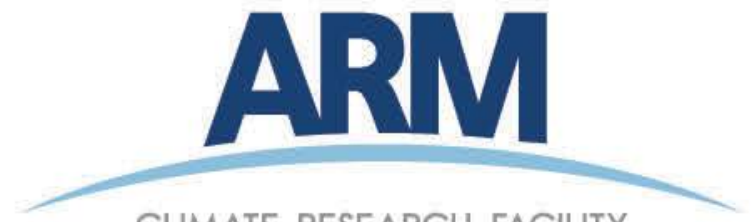

CLIMATE RESEARCH FACILITY

www.arm.gov

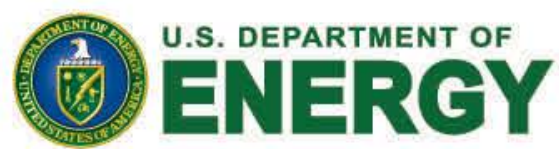

Office of Science 